\title{
Indicators Related to Learning through Facebook
}

\author{
Mayara Kaynne F. Cabral1, 2*, George França dos Santos ${ }^{1}$, Paulo César de S. Patrício², Rosária H. \\ R. Nakashima ${ }^{3}$, Albano Dias Filho ${ }^{2}$ \\ ${ }^{1}$ Federal University of Tocantins, Palmas, Brazil. \\ ${ }^{2}$ Federal Institute of Education, Science and Technology of Tocantins, Porto Nacional, Brazil. \\ ${ }^{3}$ Federal University of Tocantins, Araguaína, Brazil. \\ * Corresponding author. Email: mayarakf@ifto.edu.br \\ Manuscript submitted October 9, 2015; accepted February 18, 2016. \\ doi: 10.17706/ijeeee.2016.6.2.128-136
}

\begin{abstract}
This article aims to look for indicators to lead researches about the use of the social network Facebook in the educational process. Among the indicators, we tried to indentify how the network was set, as well as techniques, education level of the students and which are the conclusions of these researches about the use of Facebook on knowledge building. To do so, we made a research in three article index basis, looking for researches realized in the last two years. The results show that $71 \%$ of the researches about the potentiality of Facebook for learning used the questionnaire as a data collection tool; $50 \%$ of the researches concluded that the creation of Facebook groups is the option that better simulates a learning environment and $77 \%$ of them involved students with a degree. The methodologies and statistic tools used to lead the network studies were identified, as well as the average number of students involved, which varied according to the set adopted for Facebook. After reviewing these 26 researches, we found that the social network Facebook may help on teaching and learning within the formal education system, and it is a step ahead on the use of technologies on the teaching learning process.
\end{abstract}

Key words: Learning, Facebook, education.

\section{Introduction}

Social networks represent a phenomenon which has determined the way new generations of students communicate and interact through internet [1]. Allowing people to share what they know and what they think, social networks offer many opportunities in education [2]. To accompany this scenario - which is already reality in schools - the educators have to change their teaching paradigm, summoning up the students to explore the potentials of internet and social networks as mediators in the transformation of knowledge [3].

According to [4], the attempts to enjoy the educational potential of social networks led to two main aspects: the development of new social networks, specific for education, or the use of preexistent social networks along with pedagogical purposes.

Studying the use of social networks as educational environments offers an opportunity to analyze their different technological and pedagogical characteristic, which may favor the design process of learning strategies, according to the peculiarities of each educational institution, teachers and students.

Tools like social networks have the potential to embody different kinds of learning and innovative pedagogical practices [5]. With this point of view, many researchers have studied the impact of the social 
network websites on students and if the adoption of these tools in the forma teaching process would bring benefits.

Popular networks as Facebook were not conceived for learning, but for socialization and communication. However, this investigation aims to look for indicators of the researches about the use of Facebook in the educational process. Among these indicators, we try to identify how the network was set, as well as techniques, the students' education level and the conclusions of these researches about the use of Facebook on the process of knowledge building. We believe that Facebook can be used in education as a learning environment and that the mapping of previous researches about the subject may help educators to adopt this tool in their pedagogical practices.

The article is organized as follows: in section two we present the procedures adopted on this investigation; in section three we emphasize some concepts considered important for the research contextualization; in section four we present the results and discussions and, in section five, the final considerations of this research.

\section{Literature Review}

A social network website (SNW), according to [6] may be defined as web based services which allow the individuals to: 1) build a public or semi-public profile within a limited system; 2) to articulate a list of other users which whom divide a connection and 3) see and surf on their lists and on the ones made by other users.

The appearance of social networks and their widespread use by students presented new options to mediate the different ways of learning [4]. According to the author, among the different ways there is formal and informal learning. Formal learning happens within an institutional environment, as a college, where the learning process is highly structured with specific goals and appropriate support. It is projected to lead to a valid certification, through some institutional rules. In informal learning, on the other hand, the learning process is not structured and does not lead to certification. It is predominantly unintentional and is controlled by the student. It happens every day in non-educational or informal environments, like at home or workplaces.

Education institutions commonly use Learning Management Systems (LMS) as formal environments for formal learning. According to definition given by [7], LMS are softwares developed about a pedagogical methodology to enable virtual or semi-presential learning and teaching, and also offer discussion forums, file sharing, task management, class plans, chats, etc.

Informal environments are considered more favorable on the process of knowledge sharing than the formal ones [4]. In this article, social networks are seen as informal environments which may be used within an institutional environment, producing formal learning. As well as in formal learning, where there are two basic units - teacher and student - a social network can also present these entities: the teacher as a moderator and the network manager, and the student as a network user.

Similarly, we presume that the teacher is an individual with more knowledge and domain about an organized curriculum, and the student is a person with less knowledge than the teacher, and who has the expectation to be monitored and instructed in the activities that the teacher is going to organize and provide in the social network.

Social networks as Facebook have been embracing other functions in a way that made the enterprises and organizations, including education institutions, recognize the benefits of using SNWs. Although Facebook has grown tremendously in size, and despite of the fact that it is offering other functions, its main function is fundamentally the one which allows to "reconnect to lost contacts and maintain contact with friends" [8 p. 1030). 


\section{Procedures}

The methodology used on this research was the literature review. This study had the intention to identify the knowledge about the use of Facebook as a resource for the learning building. To achieve this goal we divided this study in three phases: 1) definition of the criteria used to include the social network to be used as investigation focus and the research basis, as well as the inclusion criteria of the articles identified; 2) search and selection of articles in the basis previously defined; 3) data collection on the selected articles; 4) analysis and interpretation of the extracted data; 5) presentation of the results through texts, graphics and tables.

In the first step to define which social network would be analyzed, we took into consideration the following criteria: 1) the popularity of the social network website in the Brazilian community; 2) presentation of the conceptual characteristics presented by [6] and 3) possibility of use in online environment through computers.

The results of the research produced by the Pew Research Center [9] and the Brazilian Media Research 2015 [10], both based on data from 2014, indicate that Facebook is the most popular social network in Brazil. Both studies also show a significant overlap in relation to other social networks. As Facebook also fits in the other criteria, it was chosen to be the object of this study.

In the second step we defined two criteria for the search of articles in the data basis: 1) publication after 2013, which means, published in the last two years; 2) open access, i.e., no payment required to read for full reading. Through these criteria and the key-words "Facebook" and "Learning" we selected 45 studies.

To include the studies classified in this research we defined that: 1) the article should present a case study in which Facebook was used to the knowledge building and not only as a mechanism for communication; and 2) the research should have been conducted within a learning institution. The selected articles which did not attended to these criteria were classified as excluded. The data basis which was source of the selected studies as well as the quantity of included and excluded studies were listed on Table 1. Along with the number of excluded studies we placed between parentheses the number of studies which are duplicated in different versions or basis. The number of repeated studies is included in the sum of the excluded.

Table 1. Data Basis Used on the Investigation

\begin{tabular}{lccc}
\hline Basis & Selected & Included & Excluded \\
\hline IEEE Xplore & 3 & 2 & 1 \\
\hline SciELO.org & 4 & 3 & 1 \\
\hline Science Direct Elsevier & 38 & 21 & $9(8)$ \\
\hline TOTAL & 45 & 26 & 19 \\
\hline
\end{tabular}

Table 2. Information Collected and Summarized through the Selected Articles

\begin{tabular}{ll}
\hline Data extraction & Description \\
\hline Study identification & Article title \\
\hline Year/country & Year of publication and the country of the institution where the research was realized \\
\hline Goal & Description/Summary of the research goal \\
\hline Environment configuration & Description of how Facebook was used (personal profile, group or page) \\
\hline Methodology & Methods used in the research \\
\hline Target population & Description of the people to whom the research is destined \\
\hline Education level & Education level of the people involved in the case study \\
\hline Results & Results and conclusions of the research \\
\hline Classification & Include or not in the revision \\
\hline
\end{tabular}

To the third step of data collection and extraction we selected 45 articles for full reading, with the aim to know, understand and relate the relevant information to achieve the results defined by the objective of this systematic review project. To each article we realized the data collection identifying the information about 
the variables defined on Table 2 .

\section{Results and Discussions}

Facebook basically allows the use of its resources in four different ways: through a personal profile; groups; pages; or applications. From the 26 studies included on this research we found that $50 \%$ of the researchers created and used groups on Facebook to simulate a learning environment. Other $11 \%$ used personal profiles, $4 \%$ pages and $4 \%$ applications integrated to Facebook. The other $31 \%$ used the network only to apply investigative questionnaires which were usually related to the students' view about Facebook as a learning environment (these studies [11]-[16] did not evidence in which set of the environment the questionnaires were applied).

The questionnaires were the main mechanism to collect data and identify learning, being used in $71 \%$ of the researches included. However, we identified other forms of learning accountability, like: analysis of the students' interaction in the network, number of likes and posts, interviews and textual analysis of reports. Fig. 1 shows the association of the way Facebook was set for the researches to the technique used to collect data and identify learning.

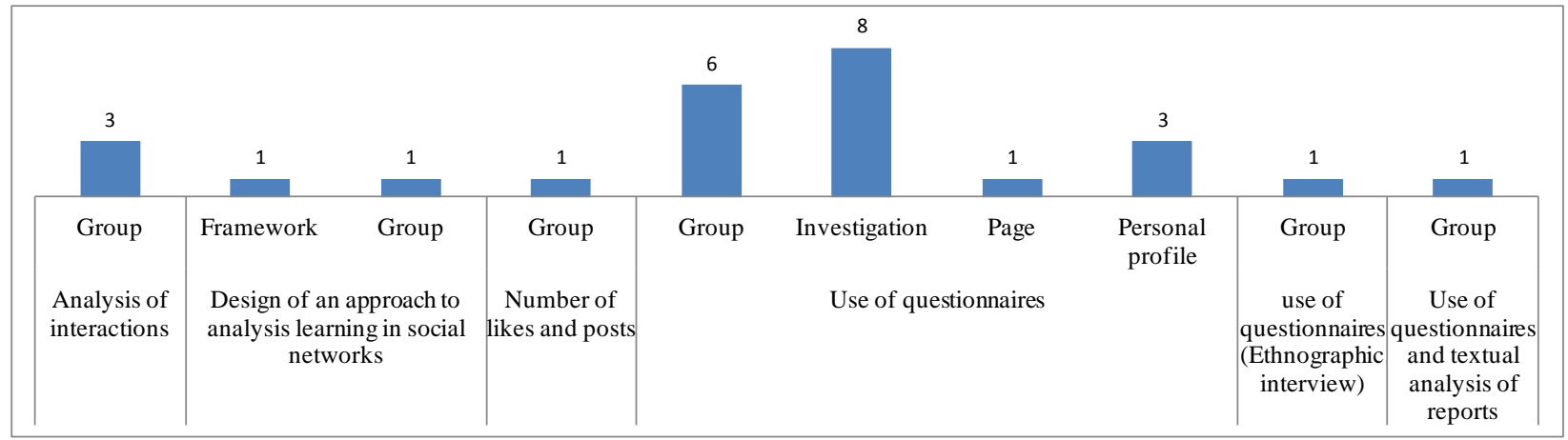

Fig. 1. Association of the Facebook set to the technique used.

Other observation is that the average quantity of students involved on the research is related to the way the network was set to the experiment. For groups, the average quantity did not get to 50 students. However, for investigations realized based on questionnaires, this number increases exponentially, as we can see on Fig. 2.

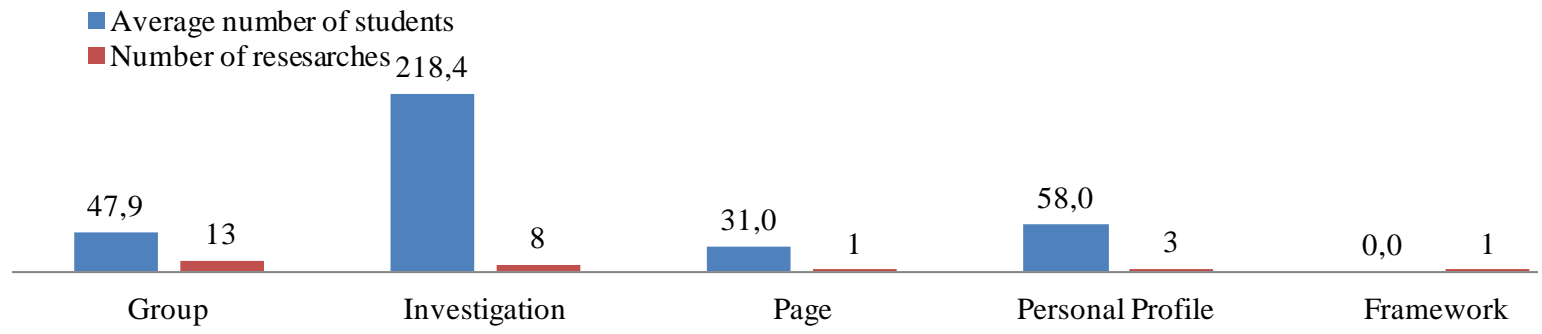

Fig. 2. Relation of the average number of students involved on the research according to the way Facebook was set.

Study [4], which used the application mentioned on Fig. 2 does not say the number of students involved, but it was the only research related to collaborative learning. The application allowed the students to build a learning material in a collaborative way under the potential moderation of a teacher. The application was purposed as a suplement to a Learning Management Systems (LMS), with the aim to reinforce the students' 
development.

On researches based on questionnaires we identified the use of many statistical tools to generate the results. We highlight that in $29 \%$ of the researches, the software SPSS Statistics was chosen; followed by Google Docs, with 23\%, and 12\% to the Survey Monkey. The other softwares identified, with 6\% of use were: Microsoft Excel, the statistics tool Anova and the software NVivo. All the tools identified are paid softwares, except Google Docs, which is completely free, and the software Survey Monkey, which has a free version limited to 10 questions and 100 answers.

During the analysis of the researches which used the questionnaire as a tool for data collection we identified the use of the chi-square test, which is a hypothesis test, and Delphi Method, a method in which the research is realized in two or more turns. In this case, after each turn, the researcher gives the results of the previous turn to the experts so they can review or maintain the original answers. The questionnaires are applied separately and the specialists do not know each other [12].

In two researches we identified the description of aproaches for learning analysis on Facebook. In the research [16], the analysis is based on a five-dimension model, embodying a set of indicators that may be used to analyze the interactions of students on Facebook. The research [4] shows multiple facets of collaboration approaches, which may increase the students' development.

Another aspect observed was that the most of the studies were directed to students with high education, corresponding to $77 \%$. Only $11 \%$ of the students involved were from high school, $4 \%$ from technical study and $8 \%$ mixed levels. Most of the target population in these studies was also students (63\%). Only one study [12] was directed to teachers. It tried to get into a consensus about the benefits of the use of Facebook as a tool for teaching and learning. Other $15 \%$ of the studies included teachers, but they were investigations realized on the network through questionnaires.

All the studies included on this review were applied by researchers connected to any formal education institutions, like universities or schools. However, we could see that, even being used within a formal educational system, Facebook, was used mostly to share academic information which was relevant to the learning process or to do researches. It was not possible to identify if there was formal learning, according to the concepts presented by [4].

In relation to the countries where the researches were developed, we found that $54 \%$ were realized in Asia, 23\% in Europe and only 15\% in America. About the year, there was a similarity between the years of 2013 and 2014 (both with 46\%). The current year - 2015 - had just 8\% of the studies.

The contents offered by the students on the social network did not follow a pattern. There were several courses and subjects, but 5 of the 26 researches were related to the teaching of a foreign language [2], [17], [18]-[20], and 2 of them aimed the exercise of writing [18], [19].

The information collected in each of the 26 studies included on this review, according to the Table 2, brought different results, most of them showing the potential of the network as an appropriate environment for the building of knowledge, like the researches [21]-[23], which compared Facebook to the environment of the Learning Management Systems (LMS).

The authors [22] and [23] found an essential coincidence of pedagogical opportunities between LMS and social networks on the evaluation process of students and teachers. Ref. [22] found that the results contradicts a popular belief that teachers and students have essential distinctions in relation to e-learning technologies and confirms the need of an integrated approach to the application of LMS and social networks on the formation of students. On the other hand, [21] identified that $67 \%$ of the interviewed prefer Facebook as a communication tool, but in comparison to LMS, Facebook provided faster answers.

About the same aspect [24] did not make a comparative investigation between the tools, but it concluded that the advantage of using Facebook as an option to the LMS discussion forums (Moodle or Blackboard) is 
that on Facebook there is real-time interaction, as well as it is offered a social environment of remote sustainable collaboration. As most of the students are used to Facebook, it allows them to interpolate their social and academic lives in the same environment, which does not happen on LMS discussion forums. The research of [24] investigated how the students evaluate the effectiveness of Facebook as a virtual learning environment during a Macroeconomics course.

In a different aspect, the research conducted by [2] found that Facebook may be used as an ice-breaker with students who present difficulties on communication, and to decrease the feeling of distance among them and the teachers, which becomes an interpersonal and relational step. However, [17] concluded that, so the different kinds of interactions really reflect on the students' learning process, it is important that the teachers use strategies which are appropriate to the environment so they can stimulate the students to be involved on the discussions over the Facebook. Ref. [19] finishes the study in the same line, emphasizing that Facebook is an effective pedagogical tool for teaching if the educators use it to guide, develop and transmit knowledge to the students.

However, some researches as [25], [26] and [11] show some negative points about the use of this network as a learning environment. It is the situation of [26], who identified that most of college students in China considered the group created on Facebook as a resource for sharing and not a space for deep discussions, which they preferred to realize face-to-face, or in a private conversation. Most of them also preferred to be "lurkers", i. e., just read what other people published or shared, hardly ever participating on discussions on the public forum. Ref. [25] used the network for teaching systems development to a group of students on the Post-graduate program in Educational Technology. The study found that the student prefer to share their opinions and ideas with their mates when it is necessary to go to a more elevated level of knowledge about a certain subject. This result is consistent to the findings of [26] and [27] which revealed the difficulties the students have on building a higher-level thought in discussions in line. On the other hand, [11] identified that most of the Information Sciences students in Mahasarakham University's considered the use of Facebook unsafe and they were afraid of having their information revealed.

\section{Final Considerations}

Even though Facebook is considered an informal learning environment, it may be used within an institutional environment, producing formal learning. According we could see in the 26 researches included on this review, the adoption of this network may favor the teaching and learning process and may be an alternative or supplementary environment to LMS. Even it does not favor a higher level of thought from the students, it presents itself as a step ahead on the stairs toward the use of new technologies on the teaching and learning process.

Contrasting to the rigidity of a LMS, the fluidity of a social network and its connection to the students' tacit knowledge offer many possibilities as a learning environment which can be used for education, teaching and different kinds of learning.

The mapping presented on this work shows that the most frequent set of Facebook as a learning tool is the creation of groups, and the most frequent way to identify learning and collect data is by questionnaires built by other tools and published on the network. These are the two main indicators which may help teachers to adopt this tool in their pedagogical practices.

But first the teachers need to understand the academic and social origins of their students, even before planning their classes and define the pedagogical techniques and the kinds of evaluations they are going to use to involve their students on the learning process. In environments like social networks, this plan is even more important because, if the educator does not use the appropriate strategies to involve the students, they will not provoke on the learners the different kinds of interactions that can favor the process. 


\section{References}

[1] Quesada, E. V. (2014). Estrategias de enseñanzapara el curso EIF-203 Estructurasdiscretasparainformática a travésdeluso de lasredessociales Facebook y Twitter. Revista Electrónica Educare, 18(2), 39-70.

[2] Saylag, R. (2013). Facebook as a tool in fostering EFL teachers' establishment of interpersonal relations with students through self-disclosure. Procedia-Social and Behavioral Sciences, 82, 680-685.

[3] Tawil, N. M., Shaari, I., Zaharim, A., Othman, H., \& Ismail, N. A. (2013). Implementing internet source as tools in teaching and learning engineering mathematics. Procedia-Social and Behavioral Sciences, 102, 122-127.

[4] Whitty, C., \& Anane, R. (2014). Social network enhancement for non-formal learning. Proceedings of 2014 47th Hawaii International Conference on System Sciences (HICSS) (pp. 1645-1654).

[5] Lucas, M., \& Moreira, A. (2009). Bridging formal and informal learning - A case study on students' perceptions of the use of social networking tools. Learning in the Synergy of Multiple Disciplines. Heidelberg, Berlin: Springer. 325-337.

[6] Body, M. D., \& Ellison, N. B. (2008). Social network sites: Definition, history, and scholarship. Journal of Computer - Mediated Communication, 13(1), 210-230.

[7] Dalsgaard, C. (2006). Social software: E-learning beyond learning management systems. European Journal of Open, Distance and e-Learning, (2).

[8] Joinson, A. N. (2008). Looking at, looking up or keeping up with people? Motives and use of Facebook. Proceedings of the SIGCHI conference on Human Factors in Computing Systems (pp. 1027-1036).

[9] Pew Research Center. (2015). Emerging nations embrace internet, mobile technology — Survey Report 2014. Retrieved September 30, 2015, from the website: http://www.pewglobal.org/2014/02/13/emerging-nations-embrace-internet-mobile-technology/

[10] Pesquisa, B. M. (2015). Hábitos de consumo de mídiapelapopulaçãobrasileira. Presidência da República. Secretaria de Comunicação Social. Brasília.

[11] Waiyahong, N. (2014). The use of "Facebook" to build an LIS student learning community. Procedia-Social and Behavioral Sciences, 147, 98-103.

[12] Noh, N. M., Razak, S. H. A., Alias, N., Siraj, S., Jamil, M. R. M., \& Hussin, Z. (2013). Usage of Facebook: The future impact of curriculum implementation on students in Malaysia. Procedia-Social and Behavioral Sciences, 103, 1261-1270.

[13] Pérez, T., Araiza, M. D. J., \& Doerfer, C. (2013). Using Facebook for learning: A case study on the perception of students in higher education. Procedia-Social and Behavioral Sciences, 106, 3259-3267.

[14] Ravichandran, P. (2014). Perception of Cambridge a-level students with respect to their technology engagement. Procedia-Social and Behavioral Sciences, 123, 28-34.

[15] DeWitt, D., Naimie, Z., \& Siraj, S. (2013). Technology applications used by first year undergraduates in a Malaysian public university. Procedia-Social and Behavioral Sciences, 103, 937-945.

[16] Said, M. N. H. M., \& Tahir, L. M. (2013). Towards identification of students' holistic learning process through Facebook in higher education. Procedia-Social and Behavioral Sciences, 97, 307-313.

[17] Juan, M., et al. (2014). Uso de Facebook para la socialización del aprendizaje de unasegundalengua en nivelmedio superior. Sinéctica, 42, 1-16.

[18] Ponnudurai, P., \& Jacob, T. T. (2014). Facebook: A shift from Social to Academia. Procedia-Social and Behavioral Sciences, 123, 122-129.

[19] Buga, R., Căpeneață, I., Chirasnel, C., \& Popa, A. (2014). Facebook in foreign language teaching - A tool to improve communication competences. Procedia-Social and Behavioral Sciences, 128, 93-98.

[20] Khonamri, F., \& Sana'ati, M. K. (2014) The impacts of dynamic assessment and call on critical reading: 
An interventionist approach. Procedia-Social and Behavioral Sciences, 98, 982-989.

[21] Mansilla, D. S., Muscia, G. C., \& Ugliarolo, E. A. (2013). Campus Virtual y Facebook en el ámbitouniversitario. Enemigos o aliados en los procesos de enseñanza y aprendizaje? Educaciónquímica, 24(2), 255-259.

[22] Mozhaeva, G., Feshchenko, A., \& Kulikov, I. (2014). E-learning in the evaluation of students and teachers: LMS or social networks? Procedia-Social and Behavioral Sciences, 152, 127-130.

[23] Eger, L. (2015). Is Facebook a similar learning tool for university students as LMS? Procedia-Social and Behavioral Sciences, 203, 233-238.

[24] Rasiah, R., \& Ratneswary, V. (2014). Transformative higher education teaching and learning: Using social media in a team-based learning environment. Procedia-Social and Behavioral Sciences, 123, 369-379.

[25] Jumaat, N. F., \& Tasir, Z. (2013). Students' types of online interaction through Facebook discussion. Procedia-Social and Behavioral Sciences, 97, 353-360.

[26] Zhang, Z. C., \& Xue, Y. (2015). An investigation of how Chinese university students use social software for learning purposes. Procedia-Social and Behavioral Sciences, 186, 70-78.

[27] Hew, K. F., \& Cheung, W. S. (2008). Attracting student participation in asynchronous online discussions: A case study of peer facilitation. Computers \& Education, 51(3), 1111-1124.

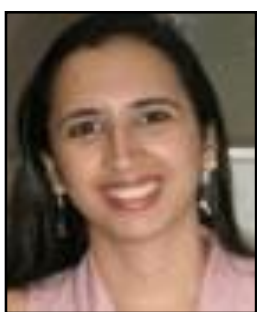

Mayara Kaynne is a professor at Instituto Federal de Educação, Ciência e Tecnologia do Tocantins (IFTO) at the graduation in Computer and at the Technical Course in Computing. She was a master student at the Postgraduate Studies Program in computational model at Universidade Federal do Tocantins. She is a specialist in database management from Faculdade Católica do Tocantins and graduated in computer science from Universidade Federal do Tocantins. She develops activities of teaching, research and extension in the fields of educational technologies and data mining. She is currently a student of the stricto sensu course in computational model at Universidade do Tocantins.

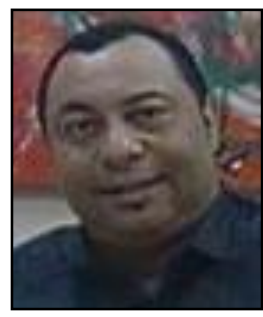

George França is a professor at Universidade Federal do Tocantins (UFT) at the graduation in language: Libras and at the Postgraduate Studies Program at computational model. He received the doctor in education (curriculum) from Pontifícia Universidade Católica, in São Paulo. He got the master degree in production and systems engineering (media e knowledge) from the same university. He is graduated in philosophy at Universidade Federal de Santa Catarina (UFSC). He develops activities of teaching, research and extention in the fields of educational technologies, distance education and phylosophy of education. He was the graduation dean at FundaçãoUniversidade do Tocantins (Unitins), as well as extension and culture dean at Universidade Federal do Tocantins. He is currently the director of Universidade Federal do Tocantins (UFT), campus Porto Nacional.

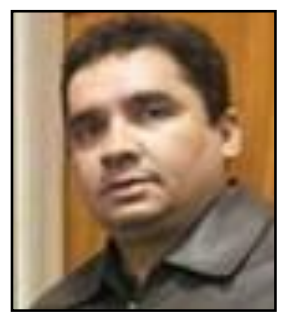

Paulo Patricio is a specialist in educational management and orientation by Faculdade do Meio Ambiente e Tecnologia de Negócios (FAMATEC); MBA in people management from Faculdade Católica do Tocantins; coursing a specialization in pedagogic coordination and school supervision at InstitutoTécnico de Educação e Cidadania (ITEC). He graduated in education from Fundação Universidade do Tocantins (Unitins), in 2009. He is currently a professor of technical and technological basic education at the campus of Porto Nacional. 


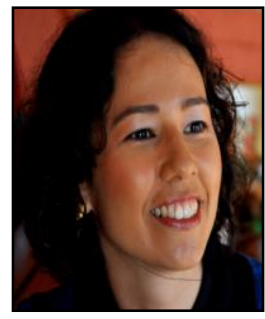

Rosária Helena Ruiz Nakashima is a professor at Universidade Federal do Tocantins (UFT) at the graduation in Pedagogy. She got the master in education at Unicamp on education, technology and digital whiteboard, the $\mathrm{PhD}$ in the field of didactics, theories of teaching and school practice, Faculdade de Educação at Universidade de São Paulo (USP). She is an associate professor, Graduate Course of History of the Universidade Federal do Tocantins (UFT). She is a professor of Interdisciplinary Graduate Program in culture and space studies (UFT). She is one member of Alpha FE / USP Group. She developed educational activities in the Virtual Training Centre of the AlfaSol Program, with training managers, teachers and students of the articulated basic education with professional education. He served as the deputy coordinator in one computer per student program (PROUCA) - Tocantins (2013-2014). Her research interests are in digital literacy in teacher education, informational literacy students and teachers, knowledge type teachers and open educational resources (OER).

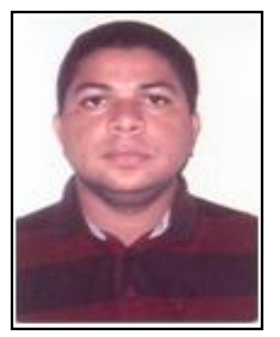

Albano Dias Filho got the master of science and mathematics teaching from the Universidade Luterana do Brasil, ULBRA. He was a doctoral student in mathematics education from the Universidade Bandeirantes, UNIBAN. He is currently a professor of mathematics and statistics degree courses in computing and logistics of the Instituto Federal de Educação, Ciência e Tecnologia do Tocantins (IFTO), Campus Porto Nacional. 